\title{
Heterozygote deficiency and population structure in the bivalve Ruditapes decussatus
}

\author{
P. BORSA, M. ZAINURI \& B. DELAY \\ Laboratoire de Génétique et Environnement, Institut des Sciences de I'Evolution (URA 327 CNRS), Université des \\ Sciences et Techniques du Languedoc, Place Eugène Bataillon, 34095 Montpellier Cedex 05, France
}

\begin{abstract}
The genetic structure of the bivalve Ruditapes decussatus from a Mediterranean lagoon was investigated at seven enzymatic loci. Samples of adults collected at the same period in different localities were genetically homogeneous. Slight allele frequency differences were observed between two annual cohorts of spat. Differences were observed between presumed cohorts of a large multicohort sample of adults. Heterozygote deficiencies were observed in multicohort samples of adults, but were not detected in cohorts of spat, nor in one sample of adults which presumably consisted of one single cohort. Thus, a relationship was found between genetic and demographic structures and is suggested to rely on the existence of differences arising through selection.
\end{abstract}

Keywords: heterozygote deficiency, population structure, Ruditapes decussatus.

\section{Introduction}

Reproductive features of numerous marine bivalve species should illustrate the classical panmictic model of population genetics. These include: release of the gametes and external fertilization, mixing and dispersion of eggs and larvae, and a long planktonic larval stage, probably dispersed by currents in what one can presume to be a random fashion over large distances before (presumably) random settling. In natural populations of bivalves, one should then observe genotype frequencies close to those expected under the Hardy-Weinberg model. However, considerable data show that departure from Hardy-Weinberg expectations, expressed as a deficiency of heterozygous phenotypes at several routinely studied enzymatic loci, is the rule in bivalves (Zouros \& Foltz, 1984; Foltz, 1986a and b; Colgan, 1987). Equally surprising are similar observations on natural populations of species that feature the same life-history characteristics as dioecious bivalves, namely sexuality, high rates of reproduction and high dispersal ability: crustaceans (Homarus: Hedgecock et al., 1977; Euphausia superba: Schneppenheim \& MacDonald, 1984), echinoderms (Ophiomusium lymani: Murphy et al., 1976; Costa \& Bisol, 1978), polychaetes (Hyalinoecia tubicola: Manwell \& Baker, 1969), gastropods (Cerithium: Ritte \& Pashtan, 1982), and flat fishes (Solea vulgaris: Kotulas, 1989).

One of the possible causes of heterozygote deficiency at a locus may be that sampling is of a mixture of individuals from two or more sub-populations which differ in allele frequencies (the Wahlund effect). For this to occur, drastic changes in allele frequencies over small geographical distances, genotype-dependent differences in time of spawning, or differential selection in time or space on clusters of larvae, which then settle at the same place, are needed. Despite the numerous reports of heterozygote deficiencies in marine invertebrates, especially in bivalves, few studies have attempted to document the role of the Wahlund effect (Tracey et al., 1975; Koehn et al., 1976; Gosling \& Wilkins, 1985). Elsewhere, the Wahlund effect was rejected simply on the basis of a genetic homogeneity observed over large distances (Koehn et al., 1973; Zouros \& Foltz, 1984).

The present work is an investigation of the genetic structure of a local population of the marine bivalve Ruditapes decussatus. In particular, it investigates to what extent a Wahlund effect, resulting from possible differences in allele frequencies (1) over the study area and (2) between presumed consecutive settling cohorts, may account for heterozygote deficiencies in this species.

\section{Materials and methods}

\section{The bivalve studied}

Ruditapes decussatus (the 'palourde') is a dioecious species, although rare juvenile hermaphroditism has been reported (Lucas, 1968). Post-larval individuals 
become totally sedentary shortly after metamorphosis. Groups of adults frequently consist of a few tens to several hundreds of individuals distributed over a few square metres. Spawning involves the liberation of about one million oocytes per female in a single spawn (P. Borsa \& A. Diter, unpublished). Fertilization takes place in the surrounding water. Eggs develop to veliger larvae, which remain planktonic for $c .10$ days at $25^{\circ} \mathrm{C}$, until complete development and growth of the foot. We observed that in hatchery conditions, about $10 \%$ of the larvae accomplish successful metamorphosis. The densities observed in spat ulteriorly do not vary very much. Therefore, high mortality rates occur before or early after settlement. Spawning was observed in the lagoon of Thau in early summer 1987 during a sudden increase in water temperature: it affected all the adults in various parts of the lagoon within less than 1 week. Thus, a cohort seemingly results from a unique reproductive event being very localized in time and therefore it is likely to consist of individuals all of the same age.

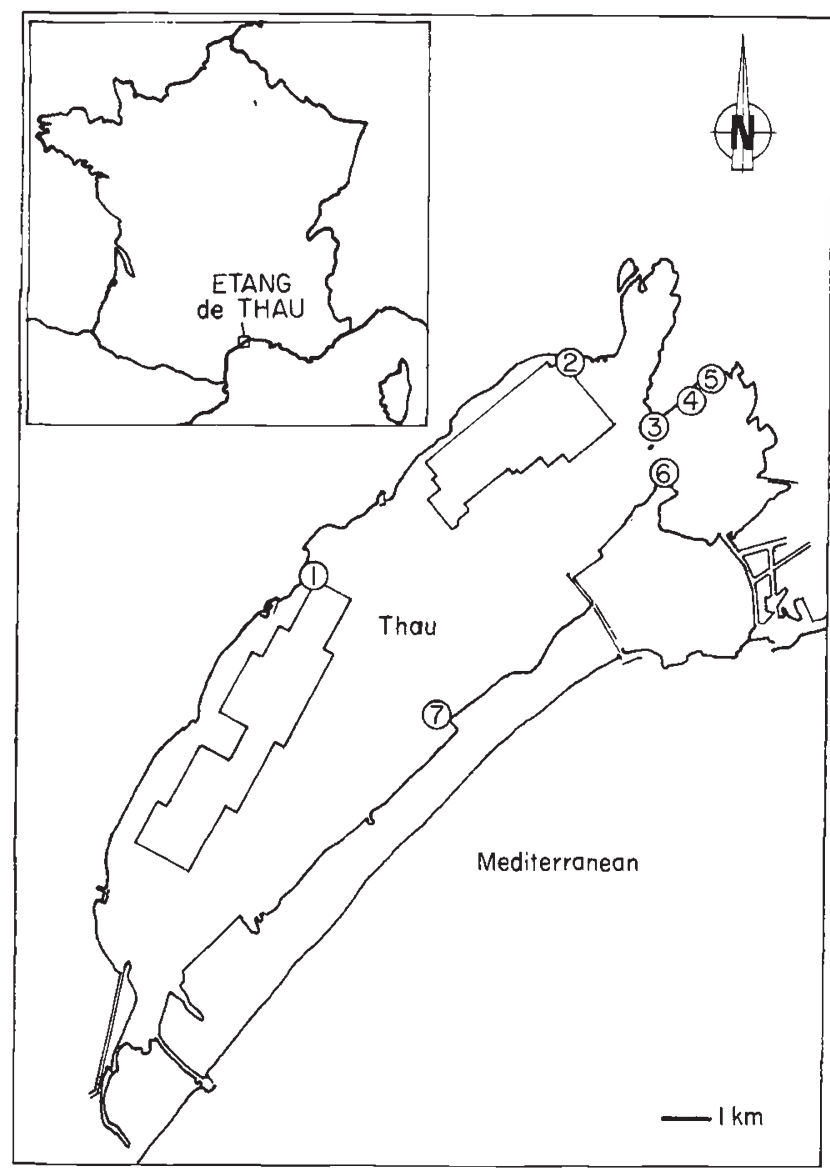

Fig. 1 Map of the Etang de Thau and location of the seven sampling sites of $R$. decussatus (see text).

\section{Sampling}

The study site was the Etang de Thau, a marine lagoon located on the French Mediterranean coast $\left(43^{\circ} 20^{\prime} \mathrm{N}\right.$; $3^{\circ} 40^{\prime} \mathrm{E}$ ) (Fig. 1).

Nine samples of palourdes were collected by sieving the sediment through a $2-\mathrm{mm}$ mesh. The seven sampling sites, located along the shore (Fig. 1), were: 1: Mourre Blanc, 2: Bouzigues, 3: Pointe Balaruc, 4: Balaruc-Port, 5: Balaruc-Z.I., 6: Barrou, 7: Lido. Two different samples were collected at sites 4 and 5 (numbered, 4, 4' and 5, 5', respectively). Samples 1-5 and 7 consisted of adults collected between May and early August 1987. Samples $4^{\prime}$ and 6 consisted of spat settled in summer 1987 and collected early in the following December. Analysis of the distribution of shell lengths (measured for each individual using a Vernier caliper) showed that all samples of adults were plurimodal (consisting of several cohorts) except sample 3 (monomodal: one presumed single cohort). The sample taken at locality 2 was large enough to compare the genetic compositions of its various (age correlated) size categories. The distribution of shell lengths in sample $4^{\prime}$ and in sample 6 was monomodal, indicating that each consisted of individuals resulting from a single spawn. Sample $5^{\prime}$ consisted of spat settled in summer 1988 and collected in early February 1989. For the latter sample, the 1988 cohort was separated from the overlapping 1987 cohort on the basis of shell length by using the statistical procedure of Bhattacharya (1967) (Fig. 2). In addition, small-sized individuals showing more than one growth-check ring (that corresponding to winter 1988-1989), were discarded on the basis that they were 1987 individuals that had

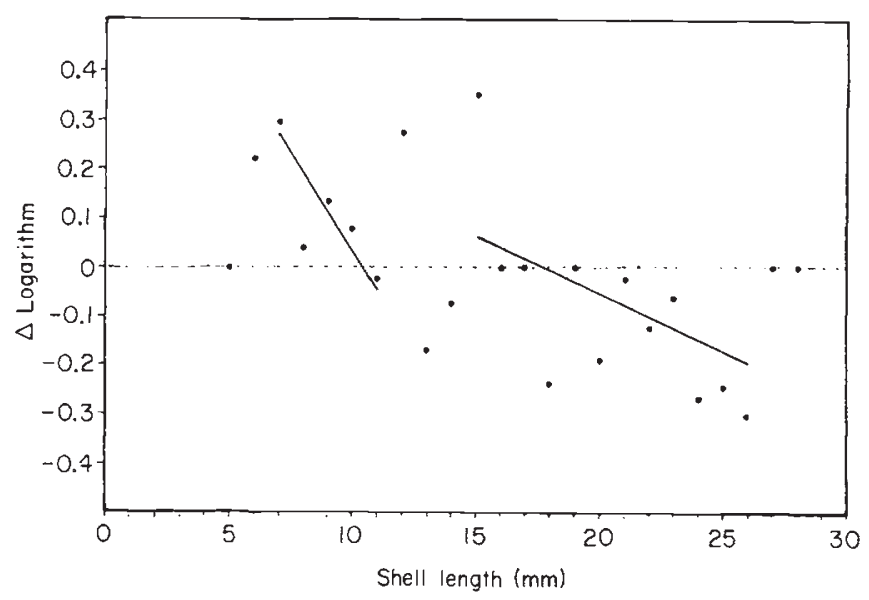

Fig. 2 Method of Bhattacharya (1967) for identification of the 1988 cohort (sample $5^{\prime}$ ) out of a sample of $R$. decussatus (Balaruc Z.I., Feb. 1989) containing individuals from both 1987 and 1988 settlements, on the basis of shell length. 
been included in the 1988 category as a result of their shell length. Therefore, sample $5^{\prime}$ was constituted of $0+(1988)$, newly settled individuals, and perhaps by a few $1+(1987)$ individuals which did not clearly exhibit more than one growth-check ring. All results concerning demographic analyses appear in Borsa (1990).

\section{Analysis of genetic polymorphism}

The specimens were stored at $-30^{\circ} \mathrm{C}$ until just before dissection and electrophoresis. The adductor muscle and the digestive gland from each individual were homogenized separately in $10 \mathrm{~mm}$ Tris/HCl/EDTA, $\mathrm{pH} 6.8$ buffer, at a ratio of approximately $1: 1 \mathrm{w} / \mathrm{v}$, and centrifuged at 7,000 $\mathrm{g}$ for $3 \mathrm{~min}$ (except for the three samples of spat, for which this protocol was carried out with the whole individual dissected from its shell). The supernatant was used as the enzyme extract. Electrophoresis was carried out on horizontal gels of $12 \%$ hydrolysed potato starch. Staining was performed for six enzymes (isocitrate dehydrogenase, malate dehydrogenase, phosphoglucomutase, esterase D, leucine aminopeptidase and glyoxalase), involving seven presumed polymorphic loci [IdhI and Idh2, Mdh1, Pgm1, EstD, Lap1 and Glo, respectively, here numbered as in Borsa \& Thiriot-Quiévreux (1990)]. Electrophoresis buffers, running methods and staining reagents were those used by Borsa \& ThiriotQuiévreux (1990), following recipes and methods detailed in Pasteur et al. (1988).

In bivalves, genetic determinism of either IDH, MDH, PGM, EST-D or LAP phenotypes was found likely to involve one single Mendelian gene (Beaumont et al., 1983; Hvilsom \& Theisen, 1984; Foltz, 1986b). This is assumed to be the case in the palourde. No breeding experiments have been attempted for testing Mendelian determinism of GLO phenotypes, but, in the palourde, the latter conformed with typically observed patterns of co-dominant allozyme inheritance.

For each sample, the fixation index per locus (Fis: Wright, 1965) was estimated by using a weighted average of the Fis calculated for each allele (Kirby, 1975). Global estimations of the 'F-statistics', namely, Fit, Fis and Fst, over either loci or samples, were done following the method and the corrections proposed by Weir \& Cockerham (1984). Following the same authors, variances around these multilocus or multisamples, monolocus $F$ values were obtained through a jackknife procedure. Testing for significance of deviations from Hardy-Weinberg expected frequencies $(F i s=0)$ was done according to Brown (1970). For $F$ values over several loci, a $t$-test was performed. Positive Fis values indicate a departure from Hardy-
Weinberg expectations towards a heterozygote deficiency, negative values an excess. Positive Fst values indicate allelic differences between samples whereas the Fst value between samples belonging to the same population or to undifferentiated populations is expected to be zero. Negative Fst values may artifactually appear, owing to the computation method of its estimator.

Chi-square of Workman \& Niswander (1970) was used in order to test for significance of $F s t$ values when the sizes of the samples compared were similar and the allelic data did not involve rare alleles. Otherwise, a homogeneity chi-square test was performed on allelic sizes with pooling of the rare alleles with alleles encoding common electromorphs of the closest mobility. It is worth noting that the statistical power of such a test must be low. This is also crucial when testing deviations from Hardy-Weinberg expected frequencies (Majumder \& Chakraborty, 1981).

\section{Results}

\section{Fixation index}

Fis values for each of the different samples of palourdes are presented in Table 1. Some positive Fis values were from very to highly significantly different from zero (Table 1). No significant negative value was observed. Moreover, distribution of Fis under panmixia is biased towards negative values at loci for which gene frequencies are extreme (Majumder \& Chakraborty, 1981; Cuguen et al., 1988), as is the case for loci Idhl, Mdhl and Glo. Therefore, actual negative Fis values are expected to be, on average, even fewer than we estimated. Fis over all loci were positive (except for samples 3 and $5^{\prime}$ ), and one of these (for sample 2) was significant $(P<0.05$; Student-Fisher $t$ test, $6 \mathrm{df})$. Though one would expect to observe by chance three significant values at $P=0.05$ in a table of 62 tests and, subsequently, these should be handled with care, the results indicate an overall tendency for departure from Hardy-Weinberg expectations towards heterozygote deficiency: five out of the seven loci examined in $R$. decussatus were out of HardyWeinberg equilibrium, all towards homozygote excess, in one or more (out of nine) samples studied. It is worth considering, however, the locus Glo as a peculiar case since this locus was the only one to exhibit a strong heterozygote deficiency in every sample. The Fis values recalculated over all loci except Glo (Table 1) yet did not noticeably decrease except for samples $4^{\prime}$ and 6 (spat). For a table of $k$ tests the variable

$\varepsilon=\Sigma(\overline{\text { Fis }} /$ s.d. $) / \sqrt{k}$ 


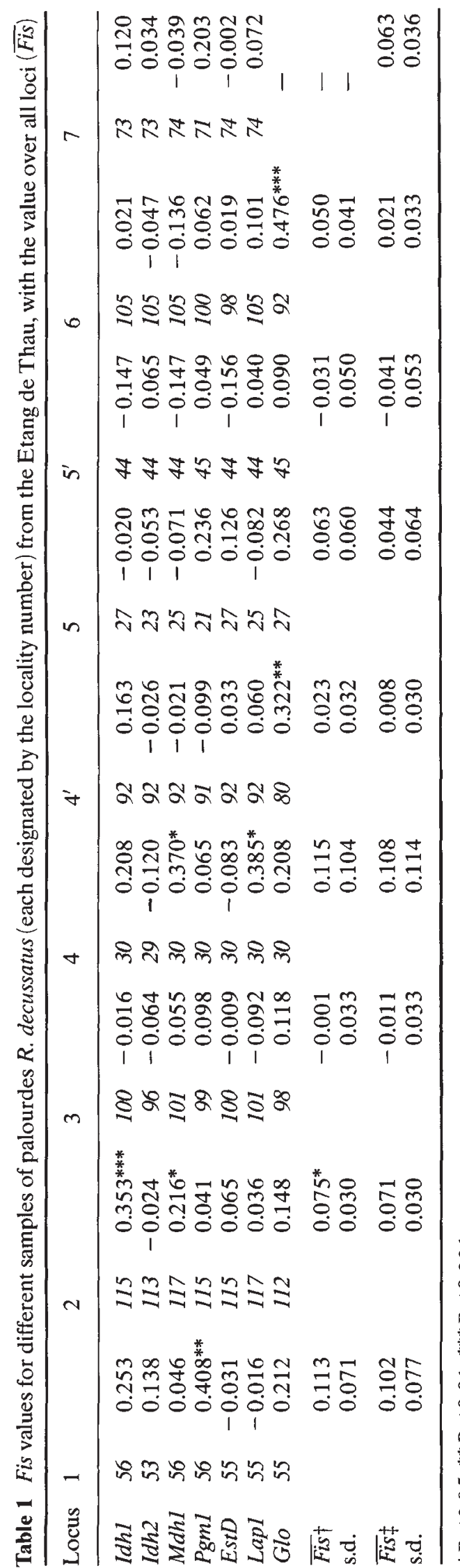

follows a $\mathscr{N}(0,1)$ distribution under the null hypothesis of equilibrium. Considering the means over all loci, its value was significant $(\varepsilon=3.095 ; P<0.01)$. Considering all loci except $G l o$, a positive value was still observed: $\varepsilon=1.594$, though on the boundary of significance $(P=0.055$; one-tailed standard normal deviate).

From Table 1, it also appears that sample 3 and the three samples of spat, namely, $4^{\prime}, 5^{\prime}$ and 6 (all four monomodal) exhibited the four lowest Fis values, while the other five samples, namely, 1, 2, 4, 5 and 7 (all plurimodal) exhibited the five largest values. Respectively, considering the mean fixation index values over all loci, $\varepsilon=0.645(P>0.51)$ for the four monomodal samples and $\varepsilon=3.576(P<0.001)$ for the other five samples. Considering all loci except Glo, we had: $\varepsilon=-0.102(P>0.91)$ and $\varepsilon=2.23(P<0.03)$, respectively.

\section{Spatial structure}

$F$-statistics values, estimated on a 'spatial' sampling that consisted of six samples $(1-5,7)$, collected in summer 1987, are presented in Table 2. At four loci (IdhI, Mdhl, Pgml and Glo) the Fit values were high. For locus Glo, Fit was significant at the $P=0.05$ level. The

Table 2 Parameters of spatial genetic structure of the palourde $R$. decussatus in the Etang de Thau. (Samples 1-5 and 7 were taken into account. See text for details.)

\begin{tabular}{|c|c|c|c|}
\hline Locus & Fit & Fis & Fst \\
\hline $\begin{array}{l}\text { IdhI } \\
\text { s.d. }\end{array}$ & $\begin{array}{l}0.166 \mathrm{~ns} \\
0.094\end{array}$ & $\begin{array}{l}0.165 \mathrm{~ns} \\
0.095\end{array}$ & $\begin{array}{l}0.001 \mathrm{~ns} \\
0.005\end{array}$ \\
\hline$I d h 2$ & $-0.011 \mathrm{~ns}$ & $-0.010 \mathrm{~ns}$ & $(-0.001) \mathrm{ns}$ \\
\hline s.d. & 0.030 & 0.031 & 0.004 \\
\hline Mdh1 & $0.090 \mathrm{~ns}$ & $0.083 \mathrm{~ns}$ & $0.007 \mathrm{~ns}$ \\
\hline s.d. & 0.051 & 0.050 & 0.010 \\
\hline Pgml & $0.149 \dagger$ & $0.145 \dagger$ & $0.004 \mathrm{~ns}$ \\
\hline s.d. & 0.061 & 0.059 & 0.008 \\
\hline$E s t D$ & $0.018 \mathrm{~ns}$ & $0.015 \mathrm{~ns}$ & $0.003 \mathrm{~ns}$ \\
\hline s.d. & 0.023 & 0.023 & 0.003 \\
\hline Lapl & $0.033 \mathrm{~ns}$ & $0.025 \mathrm{~ns}$ & $0.008 \mathrm{~ns}$ \\
\hline s.d. & 0.050 & 0.048 & 0.007 \\
\hline Glo & $0.137^{*}$ & $0.136^{*}$ & $0.001 \mathrm{~ns}$ \\
\hline s.d. & 0.038 & 0.043 & 0.010 \\
\hline Mean $\ddagger$ & $0.063 \dagger$ & $0.060 \dagger$ & $0.004 \mathrm{~ns}$ \\
\hline s.d. & 0.026 & 0.026 & 0.007 \\
\hline Mean§ & $0.057 \dagger$ & $0.054 \mathrm{~ns}$ & $0.004 \mathrm{~ns}$ \\
\hline s.d. & 0.028 & 0.028 & 0.007 \\
\hline
\end{tabular}




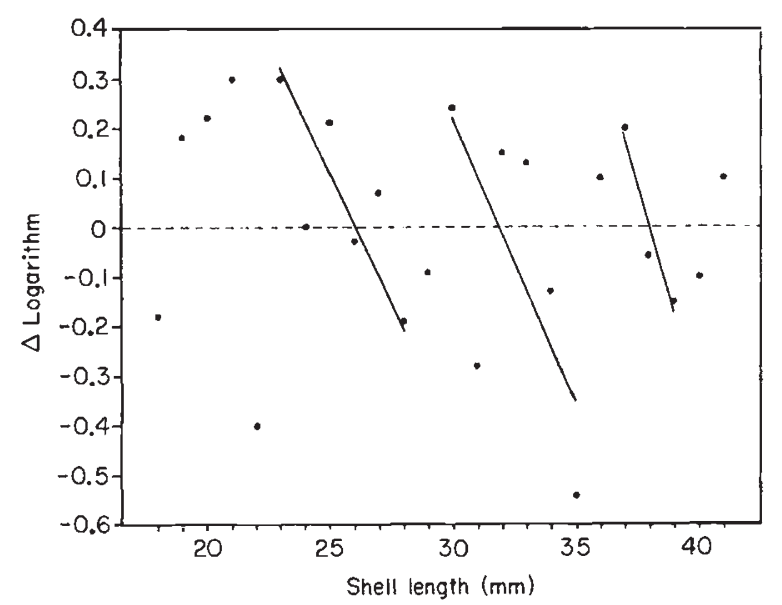

Fig. 3 Size classes (presumed cohorts) observed within sample 2 of $R$. decussatus (Bouzigues, June 1987) determined by the method of Bhattacharya (1967).

estimated overall Fit value was therefore high: Fit $=0.063$, although on the boundary of significance $(P=0.052,6 \mathrm{df}, t$-test $)$. No $F s t$ value differed significantly from zero. Therefore, departure from Hardy-Weinberg expectations was to be found within each sample (as in Table 1) whereas heterogeneity between samples did not occur or was too slight to be detected.

\section{Genotypic structure of a multicohort sample}

Sample 2, which showed a significant positive Fis value (Table 1), consisted of three presumed cohorts that were individualized using Bhattacharya's method (Fig. 3 ), and of remnants of other cohorts that were discarded for the calculations detailed below. Fis and Fst were estimated for each cohort. Mean monolocus values over all three cohorts are presented in Table 3. The estimated $F$ st value at locus $I d h l$ was very significant (Workman \& Niswander's chi-square: $\chi^{2}=13.40$, $4 \mathrm{df} ; P<0.01)$, thus indicating differences between cohorts. The other monolocus $F s t$ values were not significant. But Fis values remained high, particularly for loci IdhI and Mdhl. For example, on the basis of the allele frequencies at locus $I d h I$ in the youngest and the oldest cohorts of sample 2, respectively 0.951 and 0.818 for the most common allele, 0.049 and 0.182 for the other alleles, the heterozygote deficiency resulting from the mixture in equal proportions of the two cohorts (each supposed at equilibrium) would only be Fis $=0.044$.

\section{Comparison of monocohort spat samples}

Table 4 reports the results of two pairwise comparisons between the different samples of spat. The comparison
Table 3 Estimated Fis and Fst values for sample 2 of $R$. decussatus (Bouzigues, June 1987) after its separation into three cohorts. $n=$ average sample size per cohort. The significance of $F i$ is was tested assuming that Fis $\sqrt{n}$ is normally distributed under equilibrium, and the mean Fis through Student-Fisher $t$-test, $6 \mathrm{df}$. The significance of Fst was tested using the chi-square of Workman \& Niswander (1970)

\begin{tabular}{llcc}
\hline Locus & $n$ & Fis & \multicolumn{1}{l}{ Fst } \\
\hline Idh1 & 35.3 & $0.3831^{*}$ & $0.0316^{* *}$ \\
Idh2 & 35.7 & $-0.0438 \mathrm{~ns}$ & $0.0055 \dagger$ \\
Mdh1 & 35.7 & $0.1821 \mathrm{~ns}$ & $0.0039 \mathrm{~ns}$ \\
Pgm1 & 36.7 & $0.0145 \mathrm{~ns}$ & $(-0.0118) \mathrm{ns}$ \\
EstD & 36.0 & $0.0805 \mathrm{~ns}$ & $(-0.0070) \mathrm{ns}$ \\
Lapl & 36.7 & $0.0174 \mathrm{~ns}$ & $(-0.0069) \mathrm{ns}$ \\
Glo & 35.0 & $0.0395 \mathrm{~ns}$ & $(-0.0107) \mathrm{ns}$ \\
Mean & & $0.0618 \mathrm{~ns}$ & $(-0.0024) \mathrm{ns}$ \\
s.d. & & 0.0346 & 0.0070 \\
\hline
\end{tabular}

s.d. $=$ Standard deviation.

ns $=$ Not significant.

${ }^{*} P<0.05 ;{ }^{* *} P<0.01 ; \nmid P<0.10$.

Table 4 Fst values for pairwise comparisons of samples of spat of $R$. decussatus ( $4^{\prime}$ and 6:1987; 5': 1988). Level of significance obtained using homogeneity chi-square test

\begin{tabular}{llc}
\hline & \multicolumn{2}{l}{ Comparison } \\
\cline { 2 - 3 } Locus & $4^{\prime}$ vs. 6 & $\left(4^{\prime}+6\right) \mathrm{vs.} 5^{\prime}$ \\
\hline Idh1 & $(-0.0056) \mathrm{ns}$ & $0.0025 \mathrm{~ns}$ \\
Idh2 & $(-0.0035) \mathrm{ns}$ & $(-0.0021) \mathrm{ns}$ \\
Mdhl & $(-0.0027) \mathrm{ns}$ & $(-0.0049) \mathrm{ns}$ \\
Pgml & $0.0054 \mathrm{~ns}$ & $0.0160 \dagger$ \\
EstD & $(-0.0016) \mathrm{ns}$ & $0.0000 \mathrm{~ns}$ \\
Lapl & $(-0.0030) \mathrm{ns}$ & $(-0.0032) \mathrm{ns}$ \\
Glo & $(-0.0008) \mathrm{ns}$ & $(-0.0038) \mathrm{ns}$ \\
Mean & $(-0.0014) \mathrm{ns}$ & $0.0011 \mathrm{~ns}$ \\
\hline
\end{tabular}

$\mathrm{ns}=$ Not significant.

$\dagger P<0.1$.

between samples $4^{\prime}$ and 6 involves one single cohort of individuals, which presumably settled simultaneously in summer 1987. It also compares the pooled sample of individuals settled in $1987\left(4^{\prime}+6\right)$ to the sample of individuals settled in $1988\left(5^{\prime}\right)$. Mean Fst values were higher (though no one significant) in column 2 (1987 vs. 1988) than in column 1 (1987, Barrou vs. Balaruc), which suggests perhaps an interannual difference but no intra-annual intersites differences. Monolocus Fst could indicate a slight interannual difference at locus $I d h 1$ (not significant) and a larger differene at locus Pgml (homogeneity chi-square: $3.39,1 \mathrm{df} ; P<0.07$ ). The two pairwise comparisons $4^{\prime}$ vs. $5^{\prime}$ and 6 vs. $5^{\prime}$ were 
made for the locus $P g m l$ and yielded the following results. $F s t=0.034$ (significant: $P<0.03$ ) between samples $4^{\prime}$ and $5^{\prime}$ and $F s t=0.003$ between samples 6 and $5^{\prime}$ (the latter value being non-significant, owing perhaps to relatively small sample sizes). The difference at locus Pgml between the 1988 sample $\left(5^{\prime}\right)$ and the Balaruc-plage 1987 sample $\left(4^{\prime}\right)$ would lead to a heterozygote deficiency of Fis $=0.023$ if equal proportions of the two 1-year classes (each at equilibrium) were mixed into a single sample.

\section{Discussion}

Our data for Ruditapes decussatus (a venerid) provide further evidence for generalized heterozygote deficiency at enzymatic loci in bivalves, as found for pectinids (Beaumont \& Beveridge, 1984; Foltz \& Zouros, 1984), mytilids (Koehn et al., 1973; Tracey et al., 1975; Koehn et al., 1976; Yamanaka \& Fujio, 1984; Gosling \& Wilkins, 1985; Colgan, 1987) and ostreids (Wilkins \& Mathers, 1973; Singh \& Zouros, 1978; Buroker et al., 1979). However, in our samples, heterozygote deficiencies (locus Glo being excluded) were absent, or at most very slight, in juveniles and on average smaller than those characterizing samples of larger (older) individuals. This apparently contradicts the models proposed by Koehn et al. (1973) and Blanc \& Bonhomme (1987), in which the selective advantage of the homozygotes during early development is compensated for by heterozygote superiority in later life, and departs from the widespread observation of a greater excess of homozygotes in small individuals than in the larger (Koehn et al. 1973; Johnson \& Utter, 1975; Tracey et al. 1975; Koehn et al. 1976; SinghZouros 1978; Zouros et al. 1980; Beaumont, 1982; Zouros \& Foltz, 1987), but see Wilkins (1978).

We attempted to estimate the possibility of the existence of either spatial or temporal differences between population subunits, respectively geographical (sampling sites) or temporal (cohorts). In this respect, we shall refer to 'spatial' and 'temporal' Wahlund effects.

Apart from the Wahlund effect, and as inbreeding in $R$. decussatus is excluded owing to its reproductive biology, different explanatory hypotheses about the origin of the deficit (particularly at locus Glo, where it was systematically observed) can be raised and summarized as the following: (1) misscoring of null heterozygotes as homozygotes, (2) selection against heterozygotes before recruitment and ( 3 ) assortative fertilization.

1 Foltz (1986a; 1986b) stressed the possibility that the deficiencies may be due to the occurrence of null alleles, where null homozygotes are lethal and null heterozygotes mistakingly scored as active homozygotes. However, according to this hypothesis, one must admit either to the existence of a high mutation rate regularly generating new deficious genes or that of a strong selection favouring the null heterozygote. Nevertheless, the null allele hypothesis cannot be ruled out in $R$. decussatus until controlled pair crosses have been performed.

2 Selection against heterozygotes during the larval stage or early after settlement seems to contradict the usually observed positive relationship between heterozygosity and fitness (reviews in Mitton \& Grant, 1984 and Zouros \& Foltz, 1987). However, explanatory models, based on selection against heterozygotes during the larval stage, have been proposed (Singh \& Green, 1984; Blanc \& Bonhomme, 1987) and still remain to be tested.

3 An observation of preferential fertilization was reported in the American oyster Crassostrea virginica (Longwell \& Stiles, 1973) but the heterogametic crosses were favoured, not the homogametic ones.

Some arguments exist against the role of a 'spatial' Wahlund effect in generating heterozygote deficiencies in our samples. First, the variation in allele frequencies between samples collected over the whole lagoon was not significant. Second, since larvae may originate from a much larger geographical area, we attempted to compare the allelic frequencies in Thau with those in neighbouring lagoons. No differences were found with a sample collected in the the Etang du Prévost (Worms \& Pasteur, 1982), located c. $25 \mathrm{~km}$ from the Etang de Thau and connected to it by a navigation canal and indirectly by the sea. Moreover, only very slight differences with remote populations, such as that of the Ebra Delta, Spain, were observed (Jarne et al., 1988). The occurrence of a spatial microdifferentiation can also be excluded, since each sample consisted of individuals collected in a single patch, i.e. within a few square metres, where the environmental conditions (substrate, tidal level) were assumed to be homogeneous.

Paradoxically, genetic differences were detected between cohorts within a sample ('temporal' Wahlund effect). Our results suggest that the individuals in a single sample may be members of various age-classes that differ in allelic frequencies. Such differences could have arisen through differences in selection from year to year, from one spawn to the next within a year, or from one cluster of larvae to the other within the same spawning period. Another possible cause for these differences could be genetic drift, generated by small effective numbers of breeders. Due to the high number of eggs per female, and to the extremely high level of 
mortality until recruitment, variance in the number of successful offspring per female must be high. Likewise, the number of successful larvae per group of breeders from which they originate may vary considerably from one group to the other. Such conditions may contribute to reduce the effective sizes of breeding units.

However, the deficiencies expected under the model of admixture of differentiated populations were far lower than those actually observed. A Wahlund effect, due to the differences observed at one locus (IdhI) between two presumed cohorts of sample 2, would have consisted of an expected heterozygote deficiency of far less amplitude (by factor 10) than the observed deficiency in this sâmple. Moreover, an important departure from Hardy-Weinberg expectations remained within each presumed cohort. Likewise, the expected Wahlund effect resulting from the difference at locus Pgml between the two consecutive annual cohorts of spat would have consisted of a heterozygote deficiency value which, once again, was much lower than that actually observed in several samples.

A major result of the present study is that a relationship exists between the demographic structure and the level of heterozygote deficiency: all three samples of spat and also sample 3 , each consisting of a single monomodal cohort and presumed to result from a single spawn, did not exhibit heterozygote deficiencies (Glo excluded), whereas significant heterozygote deficiencies appeared in the other samples, consisting of individuals belonging to overlapping size (age) classes. This strongly suggests that heterozygote deficiencies may actually be the consequence of differences between cohorts. The observation of small differences between consecutive cohorts of spat would support this hypothesis, but larger differentiation (which could not be detected in the present work) is required to account for the deficits observed in multicohort samples of adults. The latter might be the consequence of increased differential selection between cohorts during the benthic stage.

In conclusion, the geographical homogeneity of $R$. decussatus in the Etang de Thau and in the neighbouring lagoons eliminates the possibility of any 'spatial' Wahlund effect. Additional data will be required to confirm the possible occurrence of a 'temporal' Wahlund effect due to differences between settling cohorts, although we expect that it will be slight. An artifact which could be due to the occurrence of null alleles seems unlikely (although this will require experimentation to be confirmed). Thus, we conclude that selection could play a major role in generating heterozygote deficiencies in $R$. decussatus, at least indirectly through a differential effect on cohorts of different ages.

\section{Acknowledgements}

We gratefully acknowledge the support and advice of D. Anxolabéhère, F. Bonhomme, and L. Thaler. B. Crouau-Roy, J. Cuguen, C. Gliddon, P. Jarne and M. Raymond helped to improve the manuscript through their comments and suggestions, and A. Callaghan and J. M. Lawrence helped to improve its form. We thank T. Do Chi for advice in demographic analysis, J. D. Lebreton and an anonymous referee for advice on statistics, and P. Cecchi for assistance with the electrophoresis. This work is contribution number 13 from ECOTHAU, a research programme supported by the French CNRS/PIREN, IFREMER and SRETIE. P. Borsa benefitted from a studentship allocated by the French Ministère de la Recherche et de la Technologie.

\section{References}

BEAUMONT, A. R. 1982. Variations in heterozygosity at two loci between year classes of a population of Chlamys opercularis (L.) from a Scottish sea loch. Mar. Biol. Lett., 3, 25-33.

BEAUMONT, A. R. AND BEVERIDGE, C. M. 1984. Electrophoretic survey of genetic variation in Pecten maximus, Chlamys opercularis, $C$. varia and $C$. distorta from the Irish Sea. Mar. Biol., 81, 299-306.

BEAUMONT, A. R., BEVERIDGE, C. M. AND BUDD, M. D. 1983. Selection and heterozygosity within single families of the mussel Mytilus edulis (L.). Mar. Biol. Lett., 4, 151-161.

BHATTACHARYA, C. G. 1967. A simple method of resolution of a distribution into Gaussian components. Biometrics, 23, $115-135$.

BLANC, F. AND BONHOMME, F. 1987. Polymorphisme génétique des populations naturelles de mollusques d'intérêt aquicole. In: Proceedings of the World Symposium on Selection, Hybridization, and Genetic Engineering in Aquaculture, Bordeaux, 27-30 May 1986, vol. 1, Berlin, pp. 59-78.

BORSA, P. 1990. Thèse de Doctorat, Université Pierre-etMarie Curie, Paris.

BORSA, P. AND THIRIOT-QUIEVREUX, c. 1990. Karyological and allozymic characterization of Ruditapes philippinarum, $R$. aureus and $R$. decussatus (Bivalvia, Veneridae). Aquaculture (in press).

BROWN, A. H. D. 1970. The estimation of Wright's fixation index from genotypic frequencies. Genetica, 41, 399-406.

BUROKER, N. E., HERSHBERGER, W. K. AND CHEW, K. K. 1979. Population genetics of the family Ostreidae. I. Intraspecific studies of Crassostrea gigas and Saccostrea commercialis. Mar. Biol., 54, 157-169.

COSTA, R. AND BISOL, P. M. Genetic variability in deep-sea organisms. Biol. Bull., 155, 125-133.

COLGAN, D. J. 1987. Deficits of heterozygotes in relation to selective interactions between loci in the mussels Brachidontes rostratus and Xenostrobus pulex. Heredity, 59, 355-362. 
CUGUEN, J., MERZEAU, D. AND THIEBAUT, B. 1988. Genetic structure of the European beech stands (Fagus sylvatica L.): Fstatistics and importance of mating system characteristics in their evolution. Heredity, 60, 91-100.

FolTZ, D. W. 1986a. Null alleles as a possible cause of heterozygote deficiency in the oyster Crassostrea virginica and other bivalves. Evolution, 40, 869-870.

FOLTZ, D. W. 1986b. Segregation and linkage studies of allozyme loci in pair crosses of the oyster Crassostrea virginica. Biochem. Genet., 24, 941-956.

FOLTZ, D. W. AND Zouros, E. 1984. Enzyme heterozygosity in the scallop Placopecten magellanicus (Gmelin) in relation to age and size. Mar. Biol. Lett., 5, 255-263.

GOSLING, E. M. AND WILKINS, N. P. 1985. Genetics of settling cohorts of Mytilus edulis (L.): preliminary observations. Aquaculture, 44, 115-123.

HEDGECOCK, D., NELSON, K., SIMONS, J. AND SHLESER, R. 1977. Genetic similarity of American and European species of the lobster Homarus. Biol. Bull., 152, 41-50.

HVILSOM, M. M. AND THEISEN, B. F. 1984. Inheritance of allozyme variations through crossing experiments with the blue mussel, Mytilus edulis L. Hereditas, 101, 1-7.

JARNE, P., BERREBI, P. AND GUELORGET, O. 1988. Variabilité génétique et morphométrique de cinq populations de la palourde Ruditapes decussatus (mollusque, bivalve). Oceanol. Acta, 11, 401-407.

JOHNSON, A. G. AND UTTER, F. M. 1975. Population differences of aspartate aminotransferase and peptidase in the bay mussel Mytilees edulis. Anim. Blood Groups Biochem. Genet, 6, 71-80.

KIRBY, G. C. 1975. Heterozygote frequencies in small subpopulations. Theor. Pop. Biol., 8, 31-48.

KOEHN, R. K., MILKMAN, R. AND MITTON, J. B. 1976. Population genetics of marine pelecypods. IV. Selection, migration and genetic differentiation in the blue mussel Mytilus edulis. Evolution, 30, 2-32.

KOEHN, R. K., TURANO, F. J. AND mitTon, J. B. 1973. Population genetics of marine pelecypods. II. Genetic differences in microhabitat of Modiolus demissus. Evolution, 27, 100-105.

Kotulas, G. 1989. Thèse de Doctorat, Université des Sciences et Techniques du Languedoc, Montpellier.

LONGWELL, A. C. AND STILES, s. s. 1973. Gamete cross incompatibilities and inbreeding in the commercial American oyster, Crassostrea virginica Gmelin. Cytologia, 38, 521-533.

LUCAS, A. 1968. Mise en évidence de l'hermaphrodisme juvénile chez Venerupis decussata (L.) (Bivalvia: Veneridae). C. R. Acad. Sci. Paris, sér. D, 367, 2332-2333.

MAJUMDER, P. P. AND CHAKRABORTY, R. 1981. Mean and variance of the number of samples showing heterozygote excess or deficiency. Heredity, 47, 259-262.

MANWELL, C. AND BAKER, C. M. A. 1969. Hybrid proteins, heterosis and the origin of species. I. Unusual variation of polychaete Hylinoecia 'nothing dehydrogenases' and of quail Coturnix erythrocyte enzymes. Comp. Biochem. Physiol., 28, 1007-1028.
MITTON, J. B. AND GRANT, M. C. 1984. Associations among protein heterozygosity, growth rate, and developmental homeostasis. Ann. Rev. Ecol. Syst., 15, 479-499.

MURPHY, L. S., ROWE, G. T. AND HAEDRICH, R. L. 1976. Genetic variability in deep-sea echinoderms. Deep Sea Res., 23, 339-348.

PASTEUR, N., PASTEUR, G., BONHOMME, F., CATALAN, J. AND BRITTONDAVIDIAN, J. 1988. Practical Isozyme Genetics. Ellis Horwood Ltd, Chichester.

RITTE, U. AND PASHTAN, A. 1982. Extreme levels of genetic variability in two Red Sea Cerithium species (Gastropoda: Cerithidae). Evolution, 36, 403-407.

SCHNEPPENHEIM, R. AND MCDONALD, C. M. 1984. Genetic variation and population structure of krill (Euphausia superba) in the Atlantic sector of Antarctic waters and off the Antarctic Peninsula. Polar Biol, 3, 19-28.

SINGH, S. M. AND GREEN, R. H. 1984. Excess of allozyme homozygosity in marine molluscs and its possible biological significance. Malacologia, 25, 569-581.

SINGH, S. M. AND ZOOROS, E. 1978. Genetic variation associated with growth rate in the American oyster (Crassostrea virginica). Evolution, 32, 342-353.

TRACEY, M. L., BELLET, N. F. AND GRAVEM, C. D. 1975. Excess allozyme homozygosity and breeding population structure in the mussel Mytilus californianus. Mar. Biol., 32, 303-311.

WEIR, B. S. AND COCKERHAM, C. C. 1984 . Estimating $F$-statistics for the analysis of population structure. Evolution, 36, 1358-1370.

WILKINS, N. P. 1978. Length-correlated changes in heterozygosity at an enzyme locus in the scallop (Pecten maximus L.). Anim. Blood Groups Biochem. Genet., 9, 69-77.

WILKINS, N. P. AND MATHERS, N. F. 1973. Enzyme polymorphism in the European oyster, Ostrea edulis L. Anim. Blood Groups Biochem. Genet., 4, 41-47.

WORKMAN, P. L. AND NiswANDER, J. D. 1970. Population studies on southwestern Indian tribes. II. Local genetic differentiation in the Papago. Am. J. Hum. Genet., 22, 24-49.

WORMS, J. AND PASTEUR, N. 1982. Polymorphisme biochimique de la palourde, Venerupis decussata, de l'Etang du Prévost (France). Oceanol. Acta, 5, 395-397.

WRIGHT, s. 1965. The interpretation of population structure by F-statistics with special regard to systems of mating. Evolution, 19, 395-420.

YAMANAKA, R. AND FUJוo, y. 1984. Heterogeneity within and between geographical populations of the Bay mussel, Mytilus edulis. Tohoku J. Agr. Res., 34, 73-84.

zouros, E. AND FOLTZ, D. w. 1984. Possible explanations of heterozygote deficiency in bivalve molluscs. Malacologia, 25, 583-591.

ZouRos, E. AND FOLTZ, D. w. 1987. The use of allelic isozyme variation for the study of heterosis. Isozymes: Curr. Topics Biol. Med. Res., 13, 1-59.

ZOUROS, E., SINGH, S. M. AND MILES, H. E. 1980. Growth rate in oysters: an overdominant phenotype and its possible explanations. Evolution, 34, 856-867. 